\title{
Optimization of customer loyalty evaluation algorithm for retail company
}

\author{
Tynchenko Vadim Sergeevich \\ (a) Dept. of Production Machinery and Equipment for \\ Petroleum and Natural Gas Engineering \\ Siberian Federal University, \\ (b) Dept. of Information Control Systems \\ Reshetnev Siberian State University of Science and \\ Technology \\ Krasnoyarsk, Russia \\ Boyko Andrei Anatolievich \\ (a) Dept. of Management \\ Siberian Federal University, \\ (b) Dept. of Management \\ Reshetnev Siberian State University of Science and \\ Technology \\ Krasnoyarsk, Russia
}

\author{
Kukartsev Vladislav Viktorovich \\ (a) Dept. of Informatics \\ Siberian Federal University, \\ (b) Dept. of Information Economic Systems \\ Reshetnev Siberian State University of Science and \\ Technology \\ Krasnoyarsk, Russia
}

\author{
Fedorova Nataiya Vladimirovna \\ Dept. of Management \\ Reshetnev Siberian State University of Science and Technology \\ Krasnoyarsk, Russia
}

\begin{abstract}
The problem of quantitative estimation of "behavioral" and "perceived" loyalty of clients is considered. The theme of the paper is to study the algorithm for filling segments, based on the Bayes formula. The methods of probability theory, mathematical statistics, cognitive modeling, regression analysis are used. The article proposes the concept of determining the quantitative evaluation of loyalty, combining "behavioral" and "perceived". The findings and results of the study are aimed at the use in retail companies, regardless of their size, specialization and the volume of the client base. In addition, the developed methods can be modified and used for analysis in other areas of business.
\end{abstract}

Keywords- Bayes formula; customer loyalty; "Behavioral" loyalty; "Perceived" loyalty; evaluation of loyalty

\section{INTRODUCTION}

Loyalty is the number of regular customers of the firm among all the number of customers who form its basic client structure and determine the volume indicators of the organization. Regular customers buy from the same company, bringing a steady income for several years, which provides the firm a relatively stable position in the market. Moreover, according to the research, keeping customers is much cheaper than attracting new ones. In this case, the more loyal the client, the easier it is to retain [1].

\section{LOYALTY MANAGEMENT}

Loyalty management (LM) includes the current assessment of customer loyalty, the formation of loyalty through programs to increase it and evaluate the effectiveness of these programs. In CRM-systems $\mathrm{LN}$, as a rule, is realized as a separate subsystem, for example, library, module, package, etc. [2-4].

Let us consider a loyalty management subsystem as an independent system, whose goal is to maximize customer loyalty. This goal is coordinated with the main purpose of using CRM - the maximum attraction of funds [5-8].

We construct the simplest model of this subsystem. In the company there are many clients $K$. Each client has a lot of personal characteristics $C$, a lot of objective quantitative indicators $O$, a lot of subjective assessments of the company's activities $D$. let us define these sets:

$$
C:\left\{c_{j}\right\}, j=\overline{1, N_{c}}
$$




$$
\begin{gathered}
O:\left\{o_{j}\right\}, j=\overline{1, N_{o}}, \\
D:\left\{d_{j}\right\}, j=\overline{1, N_{d}}, \\
K:\left\{k_{i} \mid k_{i}=\left(c_{i}, o_{i}, d_{i}\right)\right\}, i=\overline{1, N},
\end{gathered}
$$

where $N$ - number of clients in the set $K$;

$\mathrm{Nc}$ - number of personal characteristics;

No - number of objective quantitative indicators;

$\mathrm{Nd}$ - number of subjective assessments of the company's activities.

Based on the above goal, the following criterion can be formulated:

$$
L=\sum_{i=1}^{N} L K_{i} \rightarrow \max
$$

where $L$ - overall customer loyalty;

$$
L K i \text { - each customer loyalty; }
$$

$N$ - overall number of clients.

Limitations of the system may be the costs associated with loyalty programs. To achieve this goal, it is necessary to solve three tasks:

- To evaluate customer loyalty.

- To form loyalty programs on the basis of evaluation.

- To evaluate the effectiveness of the loyalty programs conducted, as shown in Fig. 1.

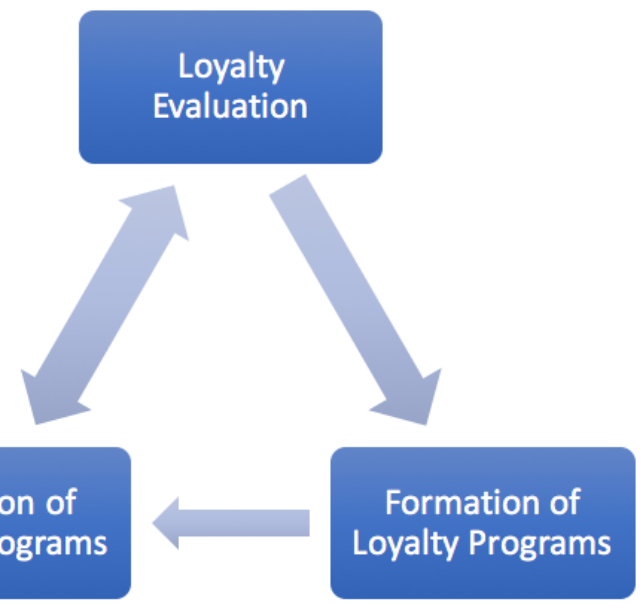

Fig. 1. Tasks of the loyalty management subsystem

\section{ETHODS OF LOYALTY EVALUATION}

The task of assessing loyalty precedes the formation of appropriate programs. The main goal of this task is to show to the person making the decision (PMD) information about the client's loyalty. Based on this and other information about the client, which can be obtained from other CRM subsystems, the decision maker can form a loyalty program, which can then be evaluated using the difference in the loyalty ratings before and after the program as a criterion $[9,10]$

In the marketing literature, there are two main approaches to solving the problem. The first is based on the consideration of loyalty as a certain type of consumer behavior, expressed in the long-term interaction with the company and the making of repeated purchases ("behavioral" loyalty). The second approach considers loyalty as a consumer preference, formed as a result of generalization of feelings, emotions, opinions about the service ("perceived" loyalty).

Both approaches have advantages and disadvantages. So, for example, the "behavioral" approach takes into account only the results of behavior, but does not disclose the reasons for which the consumer prefers a company, but allows for a relatively easy evaluation of loyalty, as it is based on objective quantitative indicators.

In contrast, the second approach can reveal the reasons for customer loyalty and reflects the future of its behavior rather than the past, but it is based on subjective opinions and assessments of customers, and there are problems in measuring this type of loyalty [11].

However, neither one nor the other kind of loyalty gives a general and holistic view of it. Therefore, within the framework of one of the classifications, the concept of complex loyalty as a combination of its two types was introduced [12]. Thus, four subtypes of complex loyalty are distinguished:

- True (absolute) loyalty is a situation where the consumer has a high level of both behavioral and perceived loyalty.

- False loyalty is a situation where a consumer has a high level of behavioral loyalty, but a low one - perceived.

- Latent loyalty - a situation that is the opposite of false loyalty.

- Lack of loyalty is a situation that is the opposite of true loyalty.

The researches in the field of assessing customer loyalty to the existing trademarks on the market began with L.P. Gesta in 1955 [13]. He suggested using the rating of the trade mark by selecting it from the list by customers according to the level of preference.

Later D. Kunnnham (1956) and subsequently K. Hammond (1996) suggested comparing brands by the duration of their use by a certain group of consumers.

In 1960, E. Pessemir developed a methodology based on the use of the maximum price of the goods, in which the client moves to another firm. 
Yakobi in 1978 suggested using a 10-point scale in the questionnaire about the client's desire to switch to another service provider. In subsequent studies, the concepts of monitoring sales with price changes, questionnaires studying the feelings and opinions of clients, etc. were proposed [14$16]$.

As for the modern research, it is possible to single out the methods proposed by MA. Bogomolova, S.M.S. Hussein, A.A. Salmin, who define "behavioral" loyalty, and the methods proposed by V.Yu. Yakovlev and A. Vellido, who define the "perceived" loyalty. Let us consider them in more detail.

Methods proposed by MA. Bogomolova, S.M. Hussein, A.A. Salmin, define "behavioral" loyalty, because they use in their basis quantitative and objective factors, and the methods proposed by V.Yu. Yakovlev and A. Vellido - "perceived," because they are based on subjective evaluative factors.

The consideration of loyalty from only one angle does not give a complete picture of it, so it is logical to consider it as a combination of "behavioral" and "perceived" loyalty.

Table 1 gives an analysis of advantages and disadvantages of the methods discussed above.

TABLE I. COMPARATIVE TABLE OF ADVANTAGES AND DISADVANTAGES OF METHODS

\begin{tabular}{|c|c|c|}
\hline $\begin{array}{l}\text { Author of } \\
\text { the method }\end{array}$ & Advantages & Disadvantages \\
\hline Bogomolova & $\begin{array}{l}\text { Decision-making is based } \\
\text { on the dynamics of } \\
\text { monetary quantitative } \\
\text { indicators }\end{array}$ & $\begin{array}{l}\text { Does not take into account } \\
\text { the personal characteristics } \\
\text { of the client }\end{array}$ \\
\hline Hussein & $\begin{array}{l}\text { Involves differentiating } \\
\text { clients according to the } \\
\text { frequency of calls and } \\
\text { cash receipts }\end{array}$ & $\begin{array}{l}\text { It is not applicable to retail } \\
\text { companies, } \\
\text { differences where } \\
\text { consumers in terms of } \\
\text { indicators may not be } \\
\text { sufficiently clear }\end{array}$ \\
\hline Salmin & $\begin{array}{l}\text { Binds loyalty to the } \\
\text { payment range, which can } \\
\text { be used in } \\
\text { telecommunication } \\
\text { companies, where } \\
\text { payments are made often } \\
\text { enough }\end{array}$ & $\begin{array}{l}\text { For retail companies, this } \\
\text { method is acceptable only } \\
\text { in the long term, since } \\
\text { money transactions are } \\
\text { relatively rare }\end{array}$ \\
\hline Yakovlev & $\begin{array}{l}\text { Loyalty is calculated on } \\
\text { the basis of the average } \\
\text { level of customer } \\
\text { satisfaction according to } \\
\text { his expectations, having } \\
\text { different specific weight }\end{array}$ & $\begin{array}{l}\text { The use of this method for } \\
\text { a large number of } \\
\text { customers is difficult }\end{array}$ \\
\hline Vellido & $\begin{array}{l}\text { It is enough to conduct a } \\
\text { questionnaire on a } \\
\text { representative sample of } \\
\text { clients and train a neural } \\
\text { network with the help of } \\
\text { the received data }\end{array}$ & $\begin{array}{l}\text { The problem of the } \\
\text { subjectivity of estimates of } \\
\text { the consumers included in } \\
\text { the sample }\end{array}$ \\
\hline
\end{tabular}

Table 2 provides an analysis of the methods discussed above in terms of the type of loyalty and the possibility of applying to the subject domain in question.
As can be seen from the table, all listed methods have some or other disadvantages, or they can be used only for the corresponding subject area.

TABLE II. COMPARISON TABLE OF METHODS

\begin{tabular}{|l|c|c|c|}
\hline $\begin{array}{c}\text { Author of } \\
\text { the method }\end{array}$ & $\begin{array}{c}\text { "Behavioral" } \\
\text { loyalty }\end{array}$ & $\begin{array}{c}\text { "Perceived" } \\
\text { loyalty }\end{array}$ & $\begin{array}{c}\text { Possibility of } \\
\text { application in } \\
\text { retail trade }\end{array}$ \\
\hline Bogomolova & + & - & Impossible \\
\hline Hussein & + & - & \begin{tabular}{c} 
Impossible \\
\hline Salmin
\end{tabular} \\
\hline Yakovlev & - & - & $\begin{array}{c}\text { Possible in the long } \\
\text { run }\end{array}$ \\
\hline Vellido & - & + & $\begin{array}{c}\text { Possible if the } \\
\text { number of clients is } \\
\text { small }\end{array}$ \\
\hline
\end{tabular}

Thus, we can draw the following conclusions. Considering loyalty from only one angle does not give a complete idea of it, so it is logical to consider it as a combination of loyalty "behavioral" and "perceived." The perceived loyalty is also difficult to measure. Proceeding from this, it turns out that the use of combining two types with a large number of customers is difficult.

\section{ALGORITHM FOR QUANTITATIVE EVALUATION OF LOYALTY BASED ON THE BAYESIAN METHOD}

The article suggests the following concept of determining the quantitative evaluation of loyalty.

The model considered above is complemented by the sets $K_{l}$ and $K_{2}$ :

$$
\begin{gathered}
K_{1}:\left\{k_{i} \mid k_{i}=\left(c_{i}, o_{i}\right)\right\}, i=\overline{1, N}, \\
K:\left\{k_{i} \mid k_{i}=\left(c_{i}, o_{i}, d_{i}\right), d_{i} \neq 0\right\}, i=\overline{1, N}, \\
K=K_{1} \cup K_{2} .
\end{gathered}
$$

A set $K_{l}$ is customers who did not participate in the survey, and a set $K_{2}$ - those who took part in it. For $K_{2}$, you can calculate "perceived" loyalty by any of the methods suggested earlier.

Let us take the method of V.Yu. Yakovlev [17]. It should be taken into account that the sample of clients for the questionnaire should be representative. For customers from the set $K_{I}$ "perceived" loyalty can not be calculated. For $i$-th client from $K_{2}$ it is calculated by the formula: 


$$
l=\frac{\sum_{j=1}^{N}\left(d_{j} W_{j}\right)}{N_{d}},
$$

where $\mathrm{j}$ - expectation number;

$$
\begin{aligned}
& d_{j} \text { - client's estimation of } j \text {-th expectation, } \\
& W_{j} \text { - specific weight of } j \text {-th expectation; } \\
& N_{d} \text { - number of estimated expectations. }
\end{aligned}
$$

To calculate the behavioral loyalty, it is proposed to use the modified method of A.A. Salmin, based on the Bayesian approach [18].

The "naive" Bayes algorithm is simple, well-scaled and has high performance. A known disadvantage is the relatively low accuracy of classification, especially in the case of binary classification.

Nowadays a large number of approaches to solving classification problems have been developed, using such algorithms as decision trees, neural networks, logistic regression, support vector method, discriminant analysis, associative rules [19-23].

From the point of view of learning speed, stability on various data and ease of implementation, the "naive" Bayes algorithm surpasses practically all known effective classification algorithms. This algorithm is preferred for the analysis of large data sets with a large number of input attributes. this connection, a modified algorithm is used, in which the prerequisites for conditional independence of attributes are relaxed.

The modification of the algorithm that solves these problems is the so-called Bayesian network.

The use of Bayesian networks avoids the problem of overfitting, that is, excessive complexity of the model, which is the weak side of many methods (for example, decision trees and neural networks).

For converting probabilities, the Bayesian formula is used:

$$
P\left(S_{k} \mid\{C\}\right)=\frac{P\left(\{C\} \mid S_{k}\right) \cdot P\left(S_{k}\right)}{\sum_{k=1}^{n} P\left(\{C\} \mid S_{k}\right) \cdot P\left(S_{k}\right)},
$$

where $P\left(S_{k} \mid\{C\}\right)$ - the probability that the client will belong to the segment $S_{k}$, provided that the client has a set of personal characteristics $C$;

$P\left(\{C\} \mid S_{k}\right)$ - the probability that the client has a set of personal characteristics $C$, provided that it belongs to the segment $S_{k}$;

$P\left(S_{k}\right)$ - a priori probability of the client's belonging to the segment $S_{k}$, obtained at the stage of stereotyping.

Segment analysis used to estimate a posteriori probability is shown in Fig. 2.

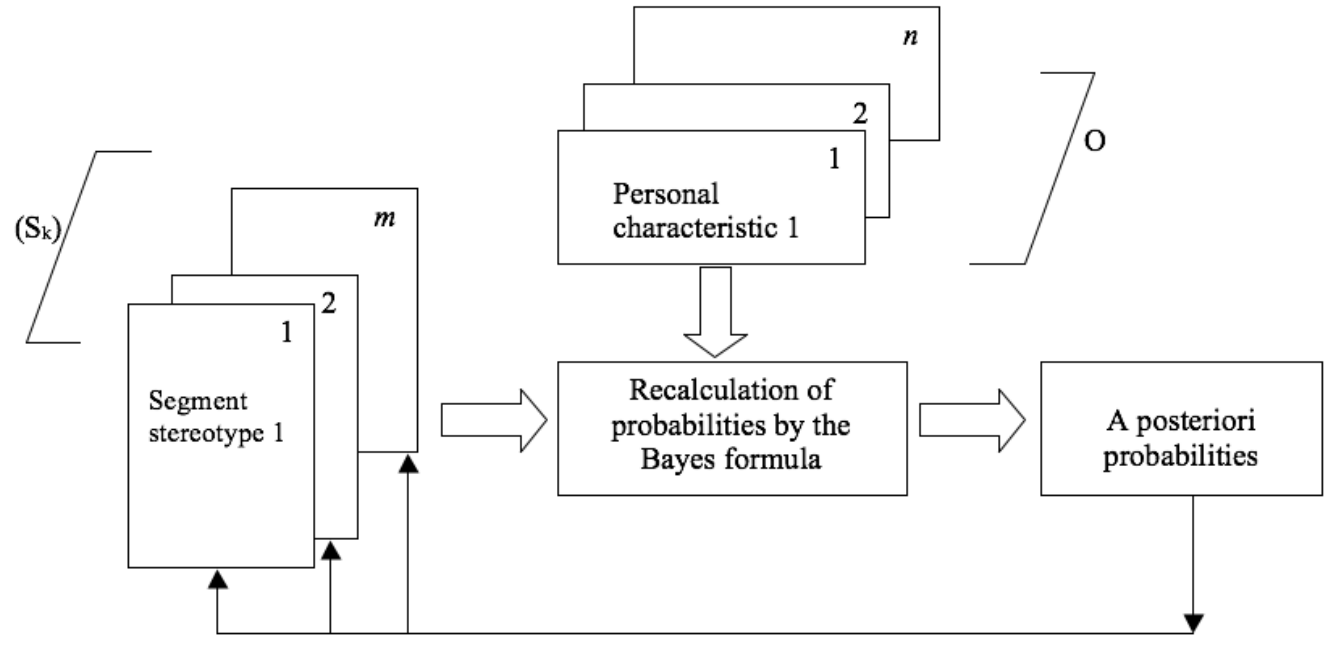

Fig. 2. The scheme of segment analysis, constructed according to the Bayes formula

The "naivety" of the algorithm lies in the assumption that the input attributes are conditionally (for each class value) independent of each other.

This assumption is very strong, and, in many cases, illegal, which makes the fact of the effectiveness of classification with the help of the "naive" Bayes algorithm quite unexpected. In
For the formation of stereotypes, it is proposed to use segmentation in terms of a number of parameters, and these parameters should include quantitative behavioral indicators of $O$.

Given that the number of parameters can be large, segment analysis is advisable to produce only by significant 
characteristics, that is, those that affect the process of segmentation of clients into segments.

The main problem in using the approach proposed by A.A. Salmin is that loyalty is compared with the customer's payment range (PR) calculated by the formula (11), in which $P\left(P R_{k}\right)$ is the probability of the client's belonging to the payment range $k$, and $P R_{k}^{l}$ and $P R_{k}{ }^{u}$ are respectively the lower and upper limits of the payment range.

$$
L=\sum_{k=1}^{N} P\left(P R_{k}\right) \cdot\left(\frac{P R_{k}^{l}+P R_{k}^{u}}{2}\right)
$$

If we consider the client's loyalty in this perspective, it turns out that the more the client brings the company's money, the more loyal it can be, which is completely wrong. Therefore, it is proposed to use another formula for calculating loyalty:

$$
L K=\sum_{k=1}^{N} P\left(S_{k}\right) \cdot L V_{k}
$$

where $L K$ - client's loyalty,

$P\left(S_{k}\right)$ - the probability of the client's belonging to the stereotype $k$, calculated as a result of segment analysis,

$L V_{k}$ - loyalty of the stereotype $k$, which can be calculated by the following formula:

$$
L V=\frac{\sum_{j=1}^{M} l_{j}}{M}
$$

where $L V$ - "perceived" customer loyalty,

$l_{j}$ - a priori evaluation of client loyalty $j$ entering segment $k$, which is suggested to use "perceived" loyalty calculated by formulas (1-5), $K_{2}$

$M$ - the number of clients in the segment $k$ entering the set

\section{CONCLUSION}

The algorithms described in the article, make it possible to implement an efficient computational process of data analysis and formation of an assessment of the "behavioral" and "perceived" customer loyalty, taking into account various influencing factors.

The paper shows that, given the current situation on the market, the use of the proposed algorithms for assessing customer loyalty is an important factor in increasing the efficiency of the retailer.
An analytical review of methods for analyzing customer loyalty has been performed, and it has been established that the most promising segment in solving these problems is analysis based on the Bayesian approach.

The proposed segmentation of data, taking into account the stereotypes of the company's clients, based on individual (personal) characteristics, allows us to make management decisions promptly and with greater certainty, as well as make appropriate forecasts.

\section{References}

[1] F. Kotler, and K.L. Keller, "Marketing management," St. Petersburg, Russia: Piter, 2007.

[2] G. Lihui, and X. Li, "An empirical study on the relationship between consumption emotions and brand loyalty," Chinese Journal of Communication, pp. 1-22, 2018.

[3] K. Ryglová, I. Rašovská, J. Šácha, and V. Maráková, "Building Customer Loyalty in Rural Destinations as a Pre-Condition of Sustainable Competitiveness," Sustainability, vol. 10(4), p. 957, 2018.

[4] S. Scheidt, and Q. B. Chung, "Making a case for speech analytics to improve customer service quality: Vision, implementation, and evaluation," International Journal of Information Management, 2018, in press.

[5] A.V. Kukartsev, and K.I. Gorlevskiya, "Principles of management of innovative business processes of the enterprise of the space-rocket industry," Economy and management of control systems, vol. 1(11), pp. 044-052, 2014.

[6] A.V. Kukartsev, K.I. Gorlevskiya, and I.V. Ogurchenok, "Management of innovative activity of the enterprise of the space-rocket industry on the basis of process approach," Economy and management of control systems, vol. 1.3(11), pp. 358-367, 2014

[7] K.I. Gorlevskiya, I.V. Ogurchenok, and A.V. Kukartsev, "Scientific approaches to management of business processes of the enterprise of the space-rocket industry," Current problems of aircraft and astronautics, vol. 2(10), pp.113-114, 2014.

[8] A.V. Kukartsev, and K.I. Gorlevskiya, "Instruments of management of business processes of the enterprise of the space-rocket industry in the competitive environment," Modern competition, vol. 5(41), pp. 81-91, 2013.

[9] A. A. Boyko, V.V. Kukartsev, K. Y. Lobkov, A.A. Stupina, " Strategic planning toolset for reproduction of machine-building engines and equipment ", J. Phys.: Conf. Ser., in press.

[10] A.A. Stupina, A.A. Shigina, A.O. Shigin, M.V. Karaseva, and S.N Ezhemanskaja, "Automated intellectual system with the short-duration nature of feedback," Life Science, vol. 11, pp. 302-306, 2014

[11] I.B. Lopatinskaja, "Loyalty as the main factor of retaining customers of banking services," Marketing in Russia and abroad, vol. 3, 2002.

[12] A.V. Cysar, "Customer loyalty: basic definitions, measurement methods, management methods," Marketing and market research, vol. 5, p. 57, 2002.

[13] F. de Oliveira Santini, W.J. Ladeira, C.H. Sampaio, and D.C. Pinto, "The brand experience extended model: a meta-analysis," Journal of Brand Management, pp. 1-17, 2018

[14] I.D. Anna, I. Cahyadi, and A. Yakin, "Model For Marketing Strategy Decision Based On Multicriteria Decicion Making: A Case Study In Batik Madura Industry,” Journal of Physics: Conference Series, vol. 953, No. 1,2018

[15] S. Tanford, E. Hwang, and S. Baloglu, "Evaluation of Reward Programs Based on Member Preferences and Perceptions of Fairness," Journal of Hospitality Marketing \& Management, vol. 27.1, pp. 106-126, 2018.

[16] A.B. Martyshev, "Marketing of relationship," Vladivostok, Russia : TIDOT FENU, p. 107, 2005

[17] V.Yu. Jakovlev, "Balanced scorecard as a tool for shaping the organization's development strategy," Kazan, Russia : Kazan State Finance and Economics Institute, p. 21, 2008. 
[18] A.A. Salmin, "Formation of loyalty estimation of the telecommunication company clients on the basis of the Bayesian approach," Samara, Russia : Volga State University of Telecommunications and Informatics, p. 132, 2008

[19] K.I. Gorlevskiya, and A.V. Kukartsev, "Regulation of innovative business processes of the enterprise of the space-rocket industry," Bulletin of the Siberian state space university of the academician M.F. Reshetnev, vol. 1(53), pp. 194-198, 2014.

[20] K.I. Gorlevskiya, I.V. Ogurchenok, and A.V. Kukartsev, "Control algorithm of innovative business processes of the enterprise of the space-rocket industry," Bulletin of the Siberian state space university of the academician M.F. Reshetnev, vol. 2(54), pp. 158-164, 2014.

[21] G.S. Klychova, A.R. Zakirova, K.Z. Mukhamedzyanov, E.R. Sadrieva, and A.S. Klychova, "Development of audit system for operations with fixed assets as a tool for efficiency improvement of social activity of the enterprise," Journal of Engineering and Applied Sciences, vol. 12(19), pp. 4966-4973, 2017.

[22] M.D. Mattei, and N. Mattei, "Analysis of fixed and biased asset allocation rebalancing strategies," Managerial Finance, vol. 42(1), pp. 42-50, 2016. 